Review

\title{
Influence of Sulfur for Oxygen Substitution in the Solvolytic Reactions of Chloroformate Esters and Related Compounds
}

\author{
Malcolm J. D'Souza ${ }^{1, \dagger, *}$ and Dennis N. Kevill ${ }^{2, \dagger, *}$ \\ 1 Department of Chemistry, Wesley College, 120 N. State Street, Dover, DE 19901-3875, USA \\ 2 Department of Chemistry and Biochemistry, Northern Illinois University, DeKalb, \\ IL 60115-2862, USA
}

$\dagger$ These authors contributed equally to this work.

* Authors to whom correspondence should be addressed;

E-Mails: dsouzama@wesley.edu (M.J.D.); dkevill@niu.edu (D.N.K.);

Tel.: +1-302-736-2528 (M.J.D.); +1-815-753-6882 (D.N.K.);

Fax: +1-302-736-2301 (M.J.D.); +1-815-753-4802 (D.N.K.).

External Editor: Habil. Mihai V. Putz

Received: 10 September 2014; in revised form: 22 September 2014 / Accepted: 29 September 2014 / Published: 10 October 2014

\begin{abstract}
The replacement of oxygen within a chloroformate ester (ROCOCl) by sulfur can lead to a chlorothioformate (RSCOCl), a chlorothionoformate (ROCSCl), or a chlorodithioformate (RSCSCl). Phenyl chloroformate $(\mathrm{PhOCOCl})$ reacts over the full range of solvents usually included in Grunwald-Winstein equation studies of solvolysis by an addition-elimination (A-E) pathway. At the other extreme, phenyl chlorodithioformate $(\mathrm{PhSCSCl})$ reacts across the range by an ionization pathway. The phenyl chlorothioformate $(\mathrm{PhSCOCl})$ and phenyl chlorothionoformate $(\mathrm{PhOCSCl})$ react at remarkably similar rates in a given solvent and there is a dichotomy of behavior with the A-E pathway favored in solvents such as ethanol-water and the ionization mechanism favored in aqueous solvents rich in fluoroalcohol. Alkyl esters behave similarly but with increased tendency to ionization as the alkyl group goes from $1^{\circ}$ to $2^{\circ}$ to $3^{\circ} . N, N$-Disubstituted carbamoyl halides favor the ionization pathway as do also the considerably faster reacting thiocarbamoyl chlorides. The tendency towards ionization increases as, within the three contributing structures of the resonance hybrid for the formed cation, the atoms carrying positive charge
\end{abstract}


(other than the central carbon) change from oxygen to sulfur to nitrogen, consistent with the relative stabilities of species with positive charge on these atoms.

Keywords: chloroformate; chlorothioformate; chlorothionoformate; chlorodithioformate; carbamoyl chloride; thiocarbamoyl chloride; Grunwald-Winstein equation; addition-elimination; ionization

\section{Introduction}

Compounds of the type $\mathrm{RO}(\mathrm{C}=\mathrm{O}) \mathrm{Cl}$ can be considered as derived from formate esters by replacement of the carbonyl-attached hydrogen by chlorine, leading to the naming as chloroformates, or as derived from half-esters of carbonic acid by replacing the hydroxyl group by chlorine, leading to naming as chlorocarbonates [1]. In the older literature, both of these systems of nomenclature can be found but current usage strongly favors the naming as chloroformates. An alternative approach to naming involves a consideration of replacing one of the chlorines of carbonyl chloride (phosgene, $\mathrm{COCl}_{2}$ ) with an alkoxy or aroxy group, to give alkoxycarbonyl or aroxycarbonyl chloride. This system of naming is the most convenient to use when these compounds are being used as reagents for the introduction of protecting groups (substituents) during peptide synthesis [2-4]. This application is extremely important and several standard abbreviations, such as $\mathrm{Z}$ for benyloxycarbonyl, Boc for tert-butoxycarbonyl, and Fmoc for 9-fluorenylmethoxycarbonyl are employed. The importance of this derivatization during peptide synthesis is illustrated by no less than 110 entries starting with " $Z$ ", 658 entries starting with "Boc", and 279 entries starting with "Fmoc" in the Sigma-Aldrich 2012-2014 Handbook of Fine Chemicals.

These groups are just three of many groupings of the ROCO-type, which are introduced, and later removed, during peptide synthesis. Chloroformates are also used in other polymer construction applications [5] and in the development of prodrugs [6].

Other halogens can replace the chlorine at the carbonyl carbon to give a family of haloformates. However, the bromoformates and iodoformates, although examples are known $[1,7,8]$, have found few applications. Fluoroformates have been appreciably studied [1,9] and they can be used where the chloroformate ester is insufficiently stable for subsequent use in derivatization or other synthetic procedures. In particular, simple tert-alkyl chloroformates are of very low stability $[1,10,11]$ but the 1-adamantyl and tert-butyl fluoroformates [12] are of considerably increased stability and they have found uses in both synthetic $[13,14]$ and mechanistic studies $[15,16]$.

Another way of modifying chloroformates (or fluoroformates) is through the replacement of oxygen by sulfur. With two non-equivalent oxygens available, three types of compound can result, as indicated, with the commonly used naming (assuming an alkyl ester), in Scheme 1.

An alkoxycarbonyl group, such as Boc, is usually subsequently removed (deprotection) by hydrolysis but the benzyloxycarbonyl group ( $Z$ ) can be removed by a catalyzed hydrogenolysis, usually with palladium as the catalyst [2]. Phenyl chlorothionoformate reacts with hydroxyl groups to give thiocarbonate esters, which can be reduced to the corresponding alkane derivative by use of the commercially available tributyltin hydride. This makes it, and similar chlorothionoformates, useful as 
reagents for initiating a deoxygenation. For example, the procedure can be used to convert ribonucleosides to deoxyribonucleosides [17,18]. For the mono-substituted derivatives, the use of "thiono" can be avoided by the use of $S$ - and $O$ - to indicate the identity of the atom to which the $\mathrm{R}$-substituent is attached in each of the two possible isomers. In this review, we will normally use the first of the names listed for each of the structures of Scheme 1.

Scheme 1. Structures and naming for sulfur-substituted alkyl chloroformates.<smiles>[R]OC(=O)Cl</smiles>

alkyl chloroformate alkoxylcarbonyl chloride<smiles>[R]OC(=S)Cl</smiles>

alkyl chlorothionoformate $O$-alkyl chlorothioformate Alkoxy(thiocarbonyl) chloride<smiles>[R]SC(=O)Cl</smiles>

alkyl chlorothioformate

$S$-alkyl chlorothioformate

(alkylthio)carbonyl chloride<smiles>[R]SC(=S)Cl</smiles>

alkyl chlorodithioformate (alkylthio)thiocarbonyl chloride

In addition to the derivatives of a chloroformate ester $(\mathrm{RO}(\mathrm{C}=\mathrm{O}) \mathrm{Cl})$ already tabulated, we can consider the replacement of the oxygen of the alkoxy group by an NR' group to give a $N, N$-disubstituted carbamoyl chloride, alternative naming as (dialkylamino)carbonyl chloride, and further, the influence of then replacing the remaining oxygen atom by a sulfur atom [19].

In the present review, we will concentrate upon the effect on reactivity of replacing one or more oxygen atoms by sulfur atoms within the substrate molecule. A useful technique is to consider the effect of varying the solvent composition on the specific rates (first-order rate coefficients) of a solvolysis reaction [20-22].

Reactions with a pathway involving rate-determining ionization will be highly sensitive to the ionizing power of the solvent, involving both overall polarity and specific solvation of the incipient ions. Reactions involving a rate-determining nucleophilic displacement of an anion will show a reduced sensitivity to changes in ionizing power and an increased sensitivity to the nucleophilicity of the solvent. Reactions involving a rate-determining addition at an unsaturated carbon atom, such as the carbonyl carbon of chloroformate esters, will show a high sensitivity to changes in solvent nucleophilicity and a reduced sensitivity to changes in solvent ionizing power, governed primarily by the solvation of the negative charge developing on the carbonyl oxygen.

Many solvolysis reactions show, even for what are generally believed to be ionization reactions, a low sensitivity to changes in solvent nucleophilicity accompanying a high sensitivity towards changes in solvent ionizing power. The reaction pathways can be considered either as involving nucleophilic solvation of the developing carbocation [23] or a loose transition state to a bimolecular $\left(\mathrm{S}_{\mathrm{N}} 2\right)$ process [24]. The activated complexes for the two processes will be very similar in structure.

These effects can be quantitated using simple and extended forms of the Grunwald-Winstein equation [20-22]. The simple form (Equation (1)) is a linear free energy relationship 


$$
\log \left(k / k_{o}\right) \mathrm{RX}=m Y+c
$$

(LFER) of the same general type as the Hammett equation [25], except there is now a consideration of the influence of changes in solvent composition for a given substrate, rather than changes in substrate structure in a fixed solvent. In Equation (1), $k$ and $k_{\mathrm{o}}$ are the specific rates of solvolysis of a substrate $\mathrm{RX}$ in a given solvent and in an arbitrarily fixed standard solvent, $m$ is a measure of the sensitivity to changes in solvent ionizing power $Y$, and $c$ is a constant (residual) term. The standard substrate was initially tert-butyl chloride and the standard solvent is $80 \%$ ethanol- $20 \%$ water (by volume at $25.0{ }^{\circ} \mathrm{C}$ ).

Equation (1) holds well when an ionization of the type $\mathrm{RX} \rightarrow \mathrm{R}^{+}+\mathrm{X}^{-}$is involved but, provided a good selection of solvent types (so as to avoid multicollinearity) are employed in the study, poorly for $\mathrm{S}_{\mathrm{N}} 2$-type reactions. This is to be expected from the neglect of the important contribution from solvent nucleophilicity. This effect can be accommodated by addition of a second term (Equation (2)), in which the sensitivity $l$ to changes in solvent

$$
\log \left(k / k_{o}\right) \mathrm{RX}=l N+m Y+c
$$

nucleophilicity $(N)$ is given consideration. The original solvent nucleophilicity scale (NOTs) is based on the solvolyses of methyl $p$-toluenesulfonate [26]. An alternative scale $\left(N_{\mathrm{T}}\right)$ based on the solvolyses of $S$-methyldibenzothiophenium ion [27], involving a neutral dibenzothiophene molecule as the leaving group, is now usually preferred. The development and uses of the Grunwald-Winstein scales of solvent nucleophilicity and solvent ionizing power have been reviewed [22,28,29].

Other techniques which can be applied towards a study of the mechanism of solvolytic reactions include the application of the Hammett equation to a series of solvolyses under uniform conditions except that a substituent is being varied in an aromatic ring situated in the vicinity of the reaction center [25]. The study of leaving-group ratios can be very useful for reactions at an acyl carbon. The $k_{\mathrm{OTs}} / k_{\mathrm{Br}}$ ratio has frequently been applied in mechanistic studies at saturated carbon [30] and, especially for studies at acyl carbon, the $k_{\mathrm{F}} / k_{\mathrm{Cl}}$ ratio [31] has been found to be very informative [32,33]. If the bond to the halogen is being broken in the rate-determining step (RDS), then very small values for the ratio are to be expected, because of the considerably stronger $\mathrm{C}-\mathrm{F}$ bond. If only a change in the hybridization influences the $\mathrm{C}-\mathrm{F}$ bond, then the stronger electron-withdrawal influences of the fluorine increases the electron deficiency at the carbonyl carbon, which favors the rate-determining addition of a nucleophilic solvent molecule and larger ratios, frequently above unity, are observed.

Entropies of activation tend to be more negative for bimolecular processes due to the need for a specific orientation of two (or more) species in the RDS. In contrast, in a unimolecular process, two ions are produced from one substrate molecule. This simple picture neglects the changes in solvation and hybridization which occur but, in practice, it is found that unimolecular reactions tend to have higher (more positive) entropies of activation than similar reactions proceeding by a bimolecular pathway [34].

Solvent deuterium isotope effects can be useful [35] but the low solubility of most organic substrates in $100 \%$ water frequently requires mixing of the $\mathrm{H}_{2} \mathrm{O}$ or $\mathrm{D}_{2} \mathrm{O}$ with an inert organic cosolvent. The situation can be simplified by use of $\mathrm{MeOH}$ and $\mathrm{MeOD}$ as the two solvents for comparison [36]. Addition-elimination (association-dissociation) substitution processes tend to involve a second nucleophilic molecule acting as a general-base [37] and this tends to raise the values for the $k_{\mathrm{MeOH}} / k_{\mathrm{MeOD}}$ ratio above the values for either conventional bimolecular or unimolecular pathways. 
The above techniques have been very useful in comparisons of the solvolytic reactivity of a "parent" chloroformate ester with the reactivity of variously-substituted derivatives [9]. In the following narrative, consideration is given to each type of sulfur-containing analog of a chloroformate ester and then brief attention will be given to the replacement of the carbonyl oxygen of an $\mathrm{N}, \mathrm{N}$-disubstituted carbamoyl chloride by sulfur. A brief survey of these topics constituted a minor contribution to an extensive (29 pages) review of the reactions of thio, thiono, and dithio analogues of carboxylic esters with nucleophiles [38]. Methods of preparation of these compounds and of $N, N$-disubstituted thiocarbamoyl halides have been summarized [39].

\section{Chlorothioformates}

An early investigation of the influence of replacing the oxygen of the alkoxy group present within chloroformate esters by sulfur was carried out by Queen et al. [40]. The specific rates of hydrolysis in $100 \% \mathrm{H}_{2} \mathrm{O}$ of a series of chlorothioformates (named as thiochloroformates in the paper [40]) were compared with corresponding values for chloroformates from an earlier study [35]. These comparisons are presented in Table 1.

Table 1. Relative specific rates for solvolyses of chloroformates and chlorothioformates esters in water at $4.6^{\circ} \mathrm{C}$.

\begin{tabular}{ccccccc}
\hline $\mathbf{R}$ & $\mathbf{P h}$ & $\mathbf{C H}_{3}$ & $\mathbf{C}_{2} \mathbf{H}_{5}$ & $\boldsymbol{n}-\mathbf{C}_{\mathbf{3}} \mathbf{H}_{7}$ & $\boldsymbol{i}-\mathbf{C}_{3} \mathbf{H}_{7}$ & $\boldsymbol{t}-\mathbf{C}_{\mathbf{4}} \mathbf{H}_{\mathbf{9}}$ \\
\hline $\mathrm{RSCOCl}$ & $1.00^{a}$ & 4.47 & 25.2 & 28.0 & 110.2 & Fast \\
$\mathrm{ROCOCl}$ & 19.4 & 0.636 & 0.388 & 0.424 & 0.958 & $b$ \\
\hline \multicolumn{6}{c}{ Specific rate of $1.060 \times 10^{-4} \mathrm{~s}^{-1} ;^{b}$ The tert-butyl chloroformate is unstable [10]. }
\end{tabular}

Queen suggested that the relative rate differences for the chlorothioformates were linked to conjugative and hyperconjugative release of electrons from the R-group into the d-orbitals of the sulfur [41]. For methyl chlorothioformate, a very thorough study at 19 temperatures, in the range of $0-20{ }^{\circ} \mathrm{C}$, led to an entropy of activation of $+6.4 \pm 0.4 \mathrm{cal} \cdot \mathrm{mol}^{-1} \cdot \mathrm{K}^{-1}$. This value is considerably higher than the value of $-19.1 \mathrm{cal} \cdot \mathrm{mol}^{-1} \cdot \mathrm{K}^{-1}$ for methyl chloroformate [35] and it was suggested, consistent with related reports [34], that these values represented unimolecular and bimolecular pathways, respectively.

The relative rates of Table 1 , as $\mathrm{R}$ is varied, show for the chloroformate a modest decrease as one goes from methyl to primary alkyl structures followed by a modest increase on going to the secondary isopropyl ester. It was suggested that this involves an addition-elimination pathway changing over to a situation with a dominant ionization pathway. For the chlorothioformate esters, a steady increase was observed from methyl to primary to secondary structures, with the continuation to the tertiary alkyl structure leading to a specific rate too large to measure by the conductometric technique employed. This suggested that an ionization pathway for solvolysis is operative across this series of substrates.

The observation for phenyl esters, that the chlorothioformate reacted about twenty times slower than the chloroformate, (a prototype for addition-elimination reaction at an acyl carbon with the addition step rate-determining [42]), indicates that, while replacement of oxygen by sulfur enhances the $\mathrm{S}_{\mathrm{N}} 1$ reactions, it retards the addition-elimination pathway. The value of twenty must be regarded as a minimum value for this retardation, since it is possible that the retardation may be sufficient to 
lead to the observation of an appreciable ionization component for the chlorothioformate. The addition-elimination and ionization pathways, in a hydroxylic solvent $(\mathrm{ROH})$, are outlined in Scheme 2.

Scheme 2. (a) Addition-Elimination Pathway; (b) Ionization Pathway.<smiles>O=C(Cl)Sc1ccccc1</smiles>

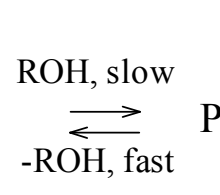<smiles>[R]OC(O)(Cl)Sc1ccccc1</smiles><smiles>[R]OC(O)(Cl)Sc1ccccc1</smiles>

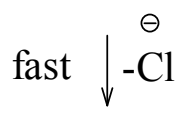

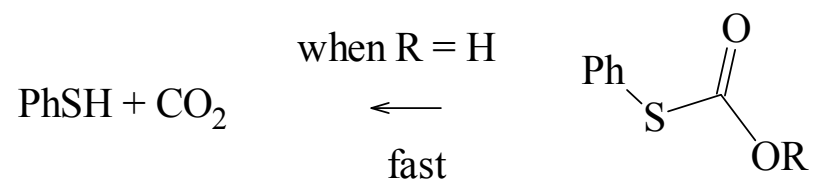

(a)

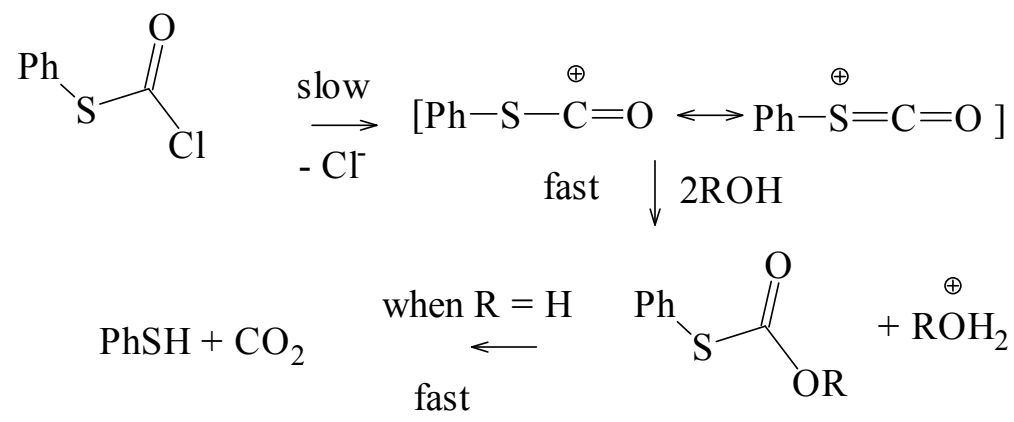

(b)

A study of the solvolysis of phenyl chlorothioformate as a function of solvent variation has been reported [43]. When the two-term Grunwald-Winstein equation [21,22] was applied, the data were best analyzed in terms of two plots. One plot was for solvents of high ionizing power and low nucleophilicity and the appreciable sensitivities to both solvent nucleophilicity and solvent ionizing power were consistent with an ionization mechanism with appreciable nucleophilic solvation of the developing acylium ion (a similar transition state would result from assignment as a loose $\mathrm{S}_{\mathrm{N}} 2$ transition state [36]). The other plot was for all other solvents and this had a higher sensitivity to changes in $N$ value and a lower sensitivity to changes in $Y$ value. This plot showing the deviation of the points for the solvents assigned to the alternative pathway, is shown in Figure 1 and the plot for these fluoroalcohol-containing solvents is shown in Figure 2. When there are two competing mechanisms with quite different $l$ and $m$ values (Equation (2)) then only solvolyses in a narrow range of solvent composition will have appreciable contributions from both mechanisms and an excellent division into two plots (as in Figures 1 and 2) can be made. 
Figure 1. Plot of $\log \left(k / k_{0}\right)$ for solvolyses of phenyl chlorothioformate at $25.0{ }^{\circ} \mathrm{C}$ against $\left(1.74 N_{\mathrm{T}}+0.48 \mathrm{Y}_{\mathrm{Cl}}\right)$. The points for the solvolyses in $\mathrm{HFIP}-\mathrm{H}_{2} \mathrm{O}$ and TFE- $\mathrm{H}_{2} \mathrm{O}$ are not used in the correlation and they are added to the plot to show the extent of their deviation from the correlation line.

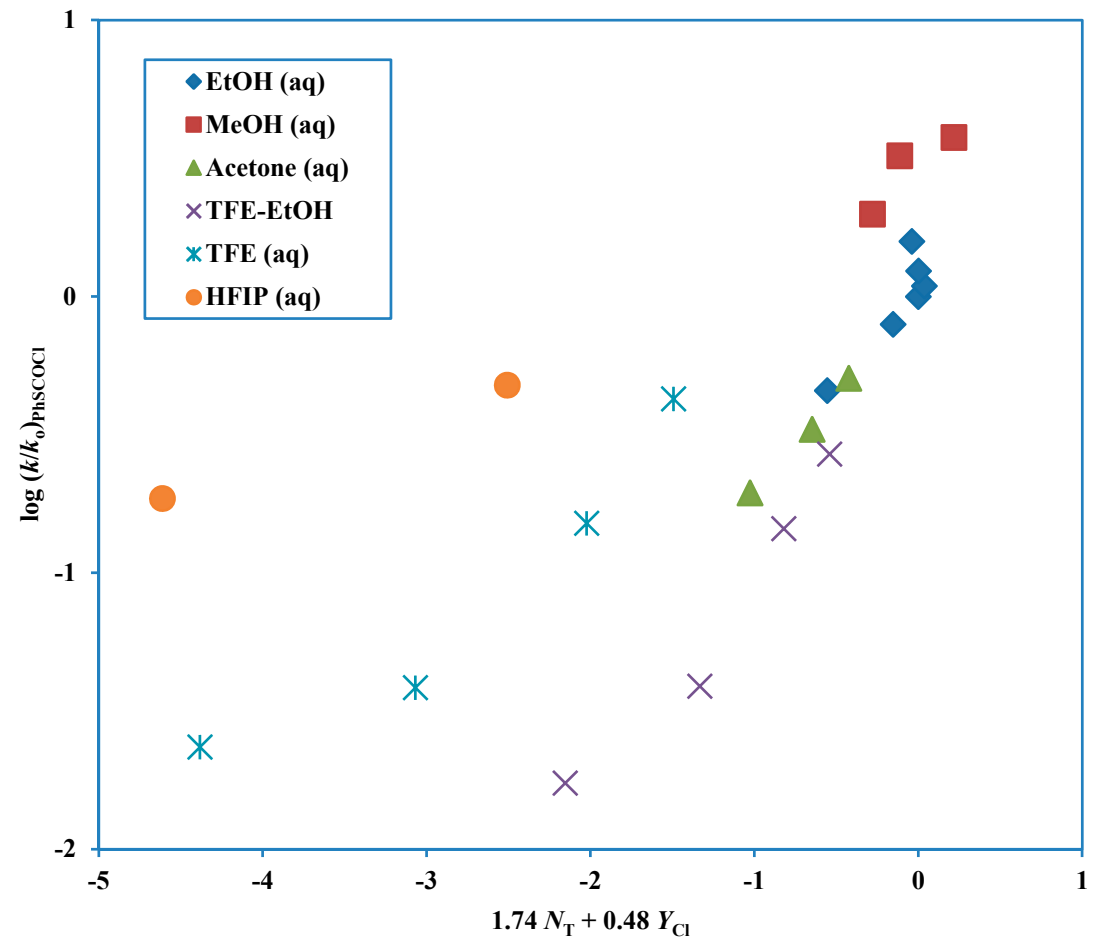

Figure 2. Plot of $\log \left(k / k_{0}\right)$ for solvolyses in $\mathrm{HFIP}-\mathrm{H}_{2} \mathrm{O}$ and $\mathrm{TFE}-\mathrm{H}_{2} \mathrm{O}$ of phenyl chlorothioformate at $25.0{ }^{\circ} \mathrm{C}$ against $\left(0.62 N_{\mathrm{T}}+0.92 Y_{\mathrm{Cl}}\right)$.

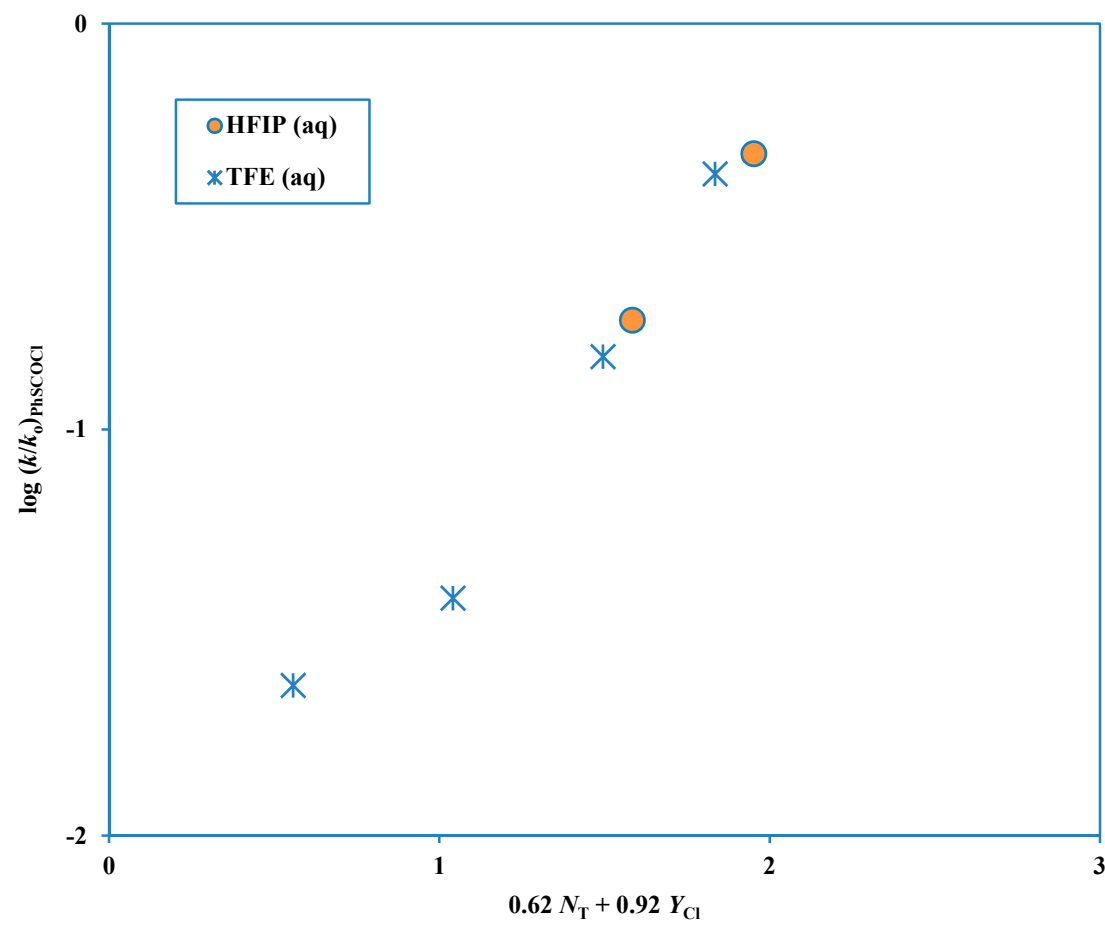


For solvolyses of the phenyl chlorothioformate in $100 \%$ water, it is possible to calculate that $91 \%$ is by ionization and only $9 \%$ by addition-elimination [43], whereas for the chloroformate essentially all of the hydrolysis is by addition-elimination [42].

Expanding the study to the solvolyses of alkyl chlorothioformates, investigations have been carried out on the solvolyses of the methyl [44], ethyl [45], isobutyl [46], isopropyl [47], and tert-butyl [48] esters. All of these solvolyses have been carried out in a selection of solvents with widely varying solvent properties and the analyses have been in terms of the Grunwald-Winstein equations (Equations (1) and (2)). Other approaches useful for assigning mechanism, as outlined in the introduction, have also been given consideration. Values obtained using Equation (2) are presented in Table 2. Also within Table 2, for comparison purposes are values for phenyl chloroformate, ethyl chloroformate, and isopropyl chloroformate and values for tert-butyl chlorothioformate obtained with the use of the one-term Grunwald-Winstein equation (Equation (1)). The observation, in some instances, of a large negative value for $c$ is an indication that the experimental $k_{\mathrm{o}}$ value, specific rate in $80 \%$ ethanol, relates to a faster alternative pathway.

Table 2. Correlation of the specific rates of solvolyses of six chlorothioformate and three chloroformate esters using the extended Grunwald-Winstein equation (Equation (2)).

\begin{tabular}{|c|c|c|c|c|c|c|c|}
\hline Substrate & $n^{a}$ & $l^{b}$ & $m^{b}$ & $c^{b}$ & $\boldsymbol{R}^{c}$ & $F^{d}$ & $l / m$ \\
\hline $\mathrm{PhOCOCl}^{e}$ & $49^{f}$ & $1.66 \pm 0.05$ & $0.56 \pm 0.03$ & $0.15 \pm 0.07$ & 0.980 & 568 & $2.96 \pm 0.18$ \\
\hline $\mathrm{PhSCOCl}^{g}$ & 16 & $1.74 \pm 0.17$ & $0.48 \pm 0.07$ & $0.19 \pm 0.23$ & 0.946 & 55 & $3.63 \pm 0.82$ \\
\hline- & 6 & $0.62 \pm 0.08$ & $0.92 \pm 0.11$ & $-2.29 \pm 0.13$ & 0.983 & 44 & $0.67 \pm 0.16$ \\
\hline $\mathrm{MeSCOCl}^{h}$ & 12 & $1.48 \pm 0.18$ & $0.44 \pm 0.06$ & $0.08 \pm 0.08$ & 0.949 & 40 & $3.36 \pm 0.84$ \\
\hline- & 8 & $0.79 \pm 0.06$ & $0.85 \pm 0.07$ & $-0.27 \pm 0.18$ & 0.987 & 95 & $0.93 \pm 0.14$ \\
\hline $\mathrm{EtOCOCl}^{e}$ & 28 & $1.56 \pm 0.09$ & $0.55 \pm 0.03$ & $0.19 \pm 0.24$ & 0.967 & 179 & $2.84 \pm 0.32$ \\
\hline- & 7 & $0.69 \pm 0.13$ & $0.82 \pm 0.16$ & $-2.40 \pm 0.27$ & 0.946 & 17 & $0.84 \pm 0.28$ \\
\hline $\mathrm{EtSCOCl}^{i}$ & 19 & $0.66 \pm 0.08$ & $0.93 \pm 0.07$ & $-0.16 \pm 0.11$ & 0.961 & 96 & $0.71 \pm 0.14$ \\
\hline$i-\mathrm{BuSCOCl}^{j}$ & 15 & $0.42 \pm 0.13$ & $0.73 \pm 0.09$ & $-0.37 \pm 0.13$ & 0.961 & 73 & $0.58 \pm 0.23$ \\
\hline$i$-PrOCOCl ${ }^{e}$ & 9 & $1.35 \pm 0.22$ & $0.40 \pm 0.05$ & $0.18 \pm 0.07$ & 0.960 & 35 & $3.38 \pm 0.92$ \\
\hline- & 16 & $0.28 \pm 0.04$ & $0.59 \pm 0.04$ & $-0.32 \pm 0.06$ & 0.982 & 176 & $0.47 \pm 0.09$ \\
\hline$i$-PrSCOCl ${ }^{k}$ & 19 & $0.38 \pm 0.11$ & $0.72 \pm 0.09$ & $-0.28 \pm 0.10$ & 0.961 & 97 & $0.53 \pm 0.18$ \\
\hline$t-\mathrm{BuSCOCl}^{l}$ & $19^{f}$ & $0.13 \pm 0.09$ & $0.80 \pm 0.06$ & $-0.03 \pm 0.07$ & 0.989 & 365 & $0.16 \pm 0.11$ \\
\hline- & $19^{f, m}$ & - & $0.73 \pm 0.03$ & $-0.10 \pm 0.05$ & 0.988 & 686 & - \\
\hline
\end{tabular}

${ }^{a}$ Number of solvents; ${ }^{b}$ With accompanying standard error; ${ }^{c}$ Multiple correlation coefficient; ${ }^{d} F$-test value;

${ }^{e}$ Data from [9]; ${ }^{f}$ Using all available solvents; ${ }^{g}$ Data from [43]; ${ }^{h}$ Data from [44]; ${ }^{i}$ Data from [45]; ${ }^{j}$ Data from [46]; ${ }^{k}$ Data from [47]; ${ }^{l}$ Data from [48]; ${ }^{m}$ This correlation is using Equation (1).

Phenyl chloroformate solvolyses across the complete range of solvents studied by a single mechanism of addition-elimination (A-E), with addition rate-determining [9,42]. However, although the corresponding chlorothioformate ester follows this mechanism over quite a large range of solvents, in fluoroalcohol-rich solvents an ionization mechanism is dominant. The six solvents rich in fluoroalcohol (2,2,2-trifluoroethanol, TFE and 1,1,1,3,3,3-hexafluoro-2-propanol, HFIP) deviate markedly from a plot based on the other solvents (Figure 1) and these solvents give a second plot (Figure 2) with a much lower sensitivity to solvent nucleophilicity and a much higher sensitivity to solvent ionizing power [43]. 
Methyl chlorothioformate solvolyzes, like the corresponding chloroformate $[9,49]$ over a large portion of the range of solvents by the A-E mechanism. There is, however, again a wider range of the more ionizing and less nucleophilic solvents for which an ionization mechanism dominates. Very similar behavior, as regards the operation of the two reaction channels, is observed for ethyl chloroformate $[9,45]$ and it appears that the introduction of sulfur for the methoxy-oxygen or the introduction of an $\alpha$-methyl group within methyl chloroformate have, in this regard, similar influences upon the division between the two reaction channels.

The ethyl chlorothioformate solvolyzes predominantly by the ionization mechanism and only in three of the studied solvents was the addition-elimination pathway dominant: ethanol, methanol, and 90\% ethanol [45]. Similarly, the primary isobutyl chlorothioformate also reacts primarily by the ionization pathway [46], with evidence for a dominant A-E pathway only in $100 \%$ and $90 \%$ ethanol, $100 \%$ and $90 \%$ methanol, and $20 \%$ TFE- $80 \%$ ethanol.

The secondary isopropyl chlorothioformate, based on the above observations coupled with the observation that isopropyl chloroformate has two fairly equally balanced regions where A-E and ionization reactions dominate $[9,50,51]$, would be expected to have the ionization pathway dominant over a large range of solvents. Indeed, only for $100 \%$ ethanol was there an upward deviation from the correlation line, indicating for this solvent a superimposed A-E pathway [47]. It has been suggested $[9,35]$ that a likely mechanism for solvolyses of $2^{\circ}$ and $3^{\circ}$ alkyl chloroformates involves a concerted fragmentation reaction (Scheme 3) leading, in the present context, to the isopropyl carbenium ion, with this then combining with the chloride ion, deprotonating to give propene plus $\mathrm{HCl}$, or adding a solvent molecule.

Scheme 3. Concerted Ionization-Fragmentation Reaction of $2^{\circ}$ and $3^{\circ}$ Alkyl Chloroformates.

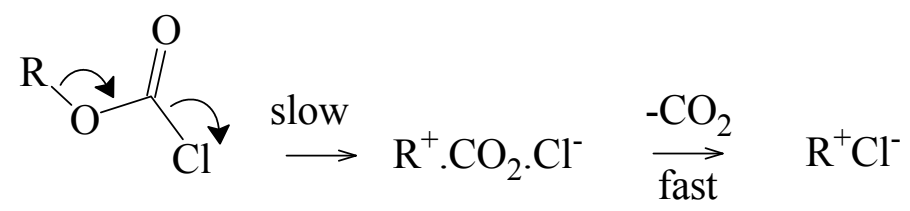

It cannot be automatically assumed that $2^{\circ}$ and $3^{\circ}$ chlorothioformates will follow this pathway, especially because, although tert-butyl chloroformate is low stability [10], the tert-butyl chlorothioformate is sufficiently stable for it to be commercially available [48]. Indeed, the observation by Queen and co-workers of 2-propanethiol as the major product from the hydrolysis in pure water of isopropyl chlorothioformate [40] requires the retention of the isopropyl-sulfur bond throughout the pathway for this solvolysis. This could be a consequence of sulfur being better able to support a positive charge in the resonance-stabilized carboxylium than oxygen (Scheme 4). It is possible that a very low stability for the carboxylium ion from the chloroformate in the presence of an electron-donating alkyl group leads to an enforced concerted process for the fragmentation [52]. 
Scheme 4. Resonance stabilized carboxylium ions from ionization of chloroformate or chlorothioformate esters.

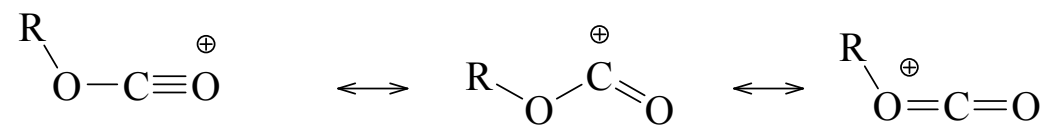

The oxygen will exert a strong affinity for electrons in the $\mathrm{R}-\mathrm{O}$ bond

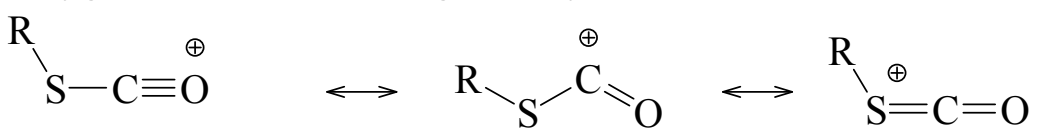

The sulfur atom better supports a positive charge

While the conditions are very different from solvolysis, it is of interest that methyl and ethyl chlorothioformates interact with antimony pentafluoride in liquid $\mathrm{SO}_{2}$ or $\mathrm{SO}_{2} \mathrm{ClF}$ to give alkylthiocarbonyl cations, with retention of $\mathrm{COS}$, while the corresponding chloroformates lose $\mathrm{CO}_{2}$ to give alkyl fluoroantimonates [53] (a rapid exchange of chlorine with fluorine in the excess $\mathrm{SbF}_{5}$ occurs). This strongly supports the thesis that the alkylthiocarbonyl cation is more stable than the corresponding alkylcarbonyl cation. Further support comes from a calculation showing that bond dissociation energies are consistent with a simple cleavage of the $\mathrm{C}-\mathrm{Cl}$ bond of a chlorothioformate being a relatively favorable process [54].

The $t$-butyl chlorothioformate shows a very low $(0.13 \pm 0.09)$ sensitivity to changes in solvent nucleophilicity coupled with a high $(0.80 \pm 0.06)$ sensitivity to changes in solvent ionizing power when the extended equation (Equation (2)) is applied. Indeed the correlation coefficient is reduced only from 0.989 to 0.988 when the original one-term Grunwald-Winstein equation (Equation (1)) is applied. As one would then predict, the $F$-test value is almost doubled on going to the one-term equation (last entry in Table 2). One can conclude that the solvolyses are best correlated by the one-term equation across the full range of solvents studied and an ionization process (Scheme 2) is operative.

The ratio of specific rates in methanol and methan (ol-d), $k_{\mathrm{MeOH}} / k_{\mathrm{MeOD}}$, was found to be $1.39 \pm 0.01$, very similar to the value for $t$-butyl fluoroformate of $1.26 \pm 0.02$ [16] and these values are within the range to be expected for a unimolecular pathway. In the trichloro-derivative of tert-butyl chloride, 2,2,2-trichloro-1,1-dimethylethyl chloroformate, the electron-withdrawing chlorides lead to an A-E mechanism [55,56] and an increased value of $2.14 \pm 0.03$ is obtained [56]. Similarly, values of $2.17 \pm 0.03$ have been obtained for $n$-propyl chloroformate [57] and of $2.03 \pm 0.01$ for isobutyl chloroformate [58] methanolyses. The higher A-E values reflect, in part, the involvement of a second methanol [or methan (ol- $d)]$ molecule as a general-base $[37,59]$.

\section{Chlorothionoformates}

In addition to their use as reagents for introducing protecting groups during peptide synthesis [3], chlorothionoformates (ROCSCl) have been found to be of use in the preparation of thiocarbonate esters, nitriles, and isonitriles $[60,61]$ and in the dealkylation of tertiary amines $[62,63]$. The important reactions with amines have been the subject of several mechanistic studies [38,64-68]. This topic has already been reviewed twice $[38,65]$ and we will mention just the interesting example of nucleophilic catalysis by pyridine in the hydrolysis of chlorothionoformate esters [66]. 
Initial mechanistic studies involved the hydrolysis in $100 \% \mathrm{H}_{2} \mathrm{O}$ and $70 \%$ acetone [69], including a comparison with the earlier studies in $100 \% \mathrm{H}_{2} \mathrm{O}$ of the corresponding chlorothioformate [40] and chloroformate [35]. At $4.8{ }^{\circ} \mathrm{C}$, in $100 \% \mathrm{H}_{2} \mathrm{O}$, it was found that, for the phenyl esters, the chlorothionoformate reacted at almost one-third the rate of the corresponding chlorothioformate ester and the reaction was 55 times slower than that for phenyl chloroformate [69].

For the identical hydrolyses of the methyl esters, the chloroformate was now the slowest, 7 times slower than the chlorothioformate and 2.6 times slower than the chlorothionoformate. For the ethyl esters, the chlorothioformate and chlorothionoformate hydrolyzed at about the same rate, which was about sixty times higher than for the chloroformate. The results can be rationalized in terms of a dominant addition-elimination pathway for the hydrolyses of the phenyl, methyl, and ethyl chloroformates, which then acquires a superimposed ionization pathway for the isopropyl ester. For the corresponding chlorothioformate, a dominant ionization pathway for the hydrolyses appears to operate over the full range of structures (see values in Table 1). The $100 \% \mathrm{H}_{2} \mathrm{O}$ solvolyses of the chlorothionoformate esters were only studied for phenyl, methyl, and ethyl, and over this limited range of structures, the relative rates $(\mathrm{Ph}, 1.0 ; \mathrm{Me}, 4.6 ; \mathrm{Et}, 68)$ were again consistent with a dominant ionization pathway.

More recent studies have concentrated on aryl chlorothionoformates. The extended Grunwald-Winstein equation (Equation (2)) has been applied to the solvolyses of phenyl chlorothionoformate [70-72], p-methylphenyl (tolyl) chlorothionoformate [73], p-chlorophenyl chlorothionoformate [73], and $p$-fluorophenyl chlorothionoformate [74]. The values obtained from these correlations are summarized in Table 3.

Table 3. Correlation of the specific rates of solvolyses of four aryl chlorothionoformates, phenyl fluorothionoformate and phenyl chlorodithioformate using the extended Grunwald-Winstein equation (Equation (2)).

\begin{tabular}{cccccccc}
\hline Substrate & $\boldsymbol{n}^{\boldsymbol{a}}$ & $\boldsymbol{l}^{\boldsymbol{b}}$ & $\boldsymbol{m}^{\boldsymbol{b}}$ & $\boldsymbol{c}^{\boldsymbol{b}}$ & $\boldsymbol{R}^{\boldsymbol{c}}$ & $\boldsymbol{F}^{\boldsymbol{d}}$ & $\boldsymbol{l} \boldsymbol{m}$ \\
\hline $\mathrm{PhOCSCl}^{e}$ & $9^{f}$ & $1.88 \pm 0.28$ & $0.56 \pm 0.15$ & $0.38 \pm 0.15$ & 0.950 & 28 & $3.36 \pm 1.36$ \\
- & $18^{g}$ & $0.34 \pm 0.05$ & $0.93 \pm 0.09$ & $-2.54 \pm 0.34$ & 0.955 & 77 & $0.37 \pm 0.08$ \\
$p-\mathrm{MeC}_{6} \mathrm{H}_{4} \mathrm{OCSCl}^{h}$ & $13^{i}$ & $1.63 \pm 0.31$ & $0.46 \pm 0.10$ & $0.30 \pm 0.12$ & 0.881 & 17 & $3.54 \pm 1.42$ \\
- & $7^{j}$ & $0.45 \pm 0.13$ & $1.07 \pm 0.14$ & $-2.25 \pm 0.20$ & 0.986 & 69 & $0.42 \pm 0.16$ \\
$p-\mathrm{FC}_{6} \mathrm{H}_{4} \mathrm{OCSCl}^{k}$ & $10^{l}$ & $1.76 \pm 0.28$ & $0.54 \pm 0.15$ & $0.34 \pm 0.15$ & 0.943 & 28 & $3.26 \pm 1.41$ \\
- & $5^{m}$ & $0.53 \pm 0.18$ & $0.89 \pm 0.18$ & $-2.66 \pm 0.35$ & 0.967 & 15 & $0.60 \pm 0.31$ \\
$p-\mathrm{ClC}_{6} \mathrm{H}_{4} \mathrm{OCSCl}^{h}$ & $13^{i}$ & $1.79 \pm 0.16$ & $0.45 \pm 0.07$ & $-0.05 \pm 0.09$ & 0.966 & 69 & $3.98 \pm 0.93$ \\
- & $6^{j}$ & $0.43 \pm 0.17$ & $0.82 \pm 0.20$ & $-3.45 \pm 0.40$ & 0.913 & 10 & $0.52 \pm 0.29$ \\
$\mathrm{PhOCSF}^{n}$ & 22 & $1.32 \pm 0.13$ & $0.39 \pm 0.08$ & $-0.02 \pm 0.10$ & 0.952 & 95 & $3.38 \pm 1.00$ \\
$\mathrm{PhSCSCl}^{o}$ & 31 & $0.69 \pm 0.05$ & $0.95 \pm 0.03$ & $0.18 \pm 0.05$ & 0.987 & 521 & $0.72 \pm 0.07$ \\
\hline
\end{tabular}

${ }^{a-d}$ See footnotes to Table 2; ${ }^{e}$ Rate data from [70] and [71] and correlation data from [72]; ${ }^{f}$ In $100 \%-80 \%$ ethanol and methanol, 80\% acetone, 80T-20E, and 60T-40E (T and E represent 2,2,2-trifluoroethanol and ethanol, respectively); ${ }^{g}$ In $\mathrm{H}_{2} \mathrm{O}, 30 \%-10 \%$ ethanol, methanol, and acetone, and all TFE- $\mathrm{H}_{2} \mathrm{O}$ and $\mathrm{HFIP}-\mathrm{H}_{2} \mathrm{O}$ solvents; ${ }^{h}$ From [73]; ${ }^{i}$ Excluding data points for TFE- $\mathrm{H}_{2} \mathrm{O}$, HFIP $\mathrm{H}_{2} \mathrm{O}$, and 80T-20E; ${ }^{j}$ For the solvents indicated as excluded in footnote $i$; ${ }^{k}$ From [74]; ${ }^{l}$ Excluding data points in 97\%-70\% HFIP and 97\%-90\% TFE; ${ }^{m}$ For the solvents indicated as excluded in footnote $l ;{ }^{n}$ From [75]; ${ }^{o}$ From [72]. 
Phenyl chlorothionoformate solvolyzes in a wide variety of solvents at a rate very close to that observed for the isomeric phenyl chlorothioformate. Further, the groupings of the solvents into those with a dominant A-E mechanism and those with a dominant ionization mechanism were similar in constitution. For eleven solvents favoring the A-E pathway the $k \mathrm{PhOCSCl} / k \mathrm{PhSCOCl}$ ratio ranged from 0.36 to 0.58 and for six fluoroalcohol-water solvents the corresponding ratio ranged from 0.97 to 1.14 [70]. McKinnon and Queen [69] had previously determined a ratio of 0.35 in $100 \% \mathrm{H}_{2} \mathrm{O}$.

Similarly the sets of $l$ and $m$ values obtained in the region involving the A-E pathway are similar to each other and, also, to those for PhOCOCl solvolyses, which follow the A-E pathway over the full range of solvents (Tables 2 and 3). Also, the values for the ionization pathway for the $\mathrm{PhSCOCl}$ and PhOCSCl show virtually identical sensitivities to changes in solvent ionizing power ( $m$ values) at 0.92 and 0.93 coupled with sensitivity towards changes in solvent nucleophilicity, somewhat greater at 0.62 for the chlorothioformate than for the chlorothionoformate, which has a value of 0.34 .

For hydrolysis in $100 \%$ water, the methyl chlorothionoformate exhibits an entropy of activation of $+13.5 \mathrm{cal} \cdot \mathrm{mol}^{-1} \cdot \mathrm{K}^{-1}[69]$, considerably higher than the value of $-19.1 \mathrm{cal} \cdot \mathrm{mol}^{-1} \cdot \mathrm{K}^{-1}$ [35] from the corresponding temperature variation study of the hydrolyses of methyl chloroformate. Also supporting the assignments of mechanism in $100 \% \mathrm{H}_{2} \mathrm{O}$ were the observations of solvent isotope effect $\left(k_{\mathrm{H}_{2} \mathrm{O}} / k_{\mathrm{D}_{2} \mathrm{O}}\right)$ of 1.28 and 1.89 , respectively [35,69].

Rumanian investigators carried out a study of the specific rates of hydrolysis of phenyl chlorothionoformate and eight ring substituted derivatives in $65 \%$ acetone [76]. They found for each substrate a very negative entropy of activation $\left(-26\right.$ to $\left.-30 \mathrm{cal} \cdot \mathrm{mol}^{-1} \cdot \mathrm{K}^{-1}\right)$ indicating all to be reacting by a bimolecular, presumably A-E, pathway.

A Hammett treatment using $\sigma^{\circ}$ values led to a $\varrho$ value of 1.26 , somewhat less than the 1.59 for the corresponding chloroformates, but still indicative of a bimolecular pathway. They found [76] similar $k_{\mathrm{H}_{2} \mathrm{O}} / k_{\mathrm{D}_{2} \mathrm{O}}$ solvent isotope effects in $65 \%$ acetone for chlorothionoformates and chloroformates. These studies strongly indicate an addition-elimination pathway with addition rate-determining for the solvolyses in $65 \%$ acetone for phenyl chlorothionoformate, based upon similarity in behavior to phenyl chloroformate, for which there is considerable evidence for the operation of such a mechanism.

Koo and coworkers reported [71] on the solvolyses of phenyl chlorothionoformate in methanol-water and ethanol-water over the full range of solvent composition, including the pure solvents, and also $80 \%-10 \%$ acetone-water. Although they had 29 data points, their overall mix of solvents was not good and in particular no solvents containing a fluoroalcohol were included in the study. Where their data coincided there was excellent agreement in the alcohol-solvents and fair agreement for two acetone-water solvents with a slightly earlier submitted report [70]. Their data was useful in a subsequent comprehensive Grunwald-Winstein equation analysis [72], discussed earlier and reported in Table 3. They obtained a $k \mathrm{MeOH} / k_{\mathrm{MeOD}}$ value of 2.02 and a $k_{\mathrm{H}_{2} \mathrm{O}} / k_{\mathrm{D}_{2} \mathrm{O}}$ value of 1.45 in $10 \%$ water, values consistent with a bimolecular pathway in methanol and a predominantly ionization pathway in water.

The previously discussed Hammett plots [76,77], for hydrolysis in $65 \%$ acetone, indicated a rate-determining nucleophilic attack. More recently, extensive Grunwald-Winstein correlations have been carried out with the electron supplying $p$-Me substituent and the electron-withdrawing $p$ - $\mathrm{Cl}$ substituent at $25.0{ }^{\circ} \mathrm{C}$ [73]. Both of these substrates and also one with the $p$-F substituent at $35.0{ }^{\circ} \mathrm{C}[74]$ show a break in the G-W correlations which is consistent with that observed for the 
parent $(p-\mathrm{H})$ compound. This behavior indicated an A-E pathway and, for the solvents rich in fluoroalcohol, an ionizing pathway (Table 3). This dichotomy can be shown, in simple terms, from relative-rates in two extreme solvents: $100 \% \mathrm{EtOH}$ and $97 \%$ HFIP. In $100 \% \mathrm{EtOH}$, at $25.0{ }^{\circ} \mathrm{C}$, the relative rates are $p-\mathrm{Me}, 1.0 ; p-\mathrm{H}, 2.1 ; p-\mathrm{Cl}, 10.5$, consistent with electron-withdrawing substituent favoring a rate-determining nucleophilic attack. In 97\% HFIP, the order of the relative rates is reversed: $p$-Me, $1.0 ; p-\mathrm{H}, 0.40 ; p-\mathrm{Cl}, 0.046$, consistent with electron-withdrawal substituents hindering the ionization reaction involving expulsion of a chloride anion. The extended Grunwald-Winstein equation plot for the addition-elimination pathway is shown in Figure 3.

Figure 3. Plot of $\log \left(k / k_{0}\right)$ for solvolyses of $p$-chlorophenyl chlorothionoformate against $\left(1.79 N_{\mathrm{T}}+0.45 Y_{\mathrm{Cl}}\right)$ in nineteen pure and binary solvents. The points for the solvolyses in $\mathrm{HFIP}-\mathrm{H}_{2} \mathrm{O}$ and TFE- $\mathrm{H}_{2} \mathrm{O}$ are not used in the correlation and they are added to the plot to show the extent of their deviation from the correlation line.

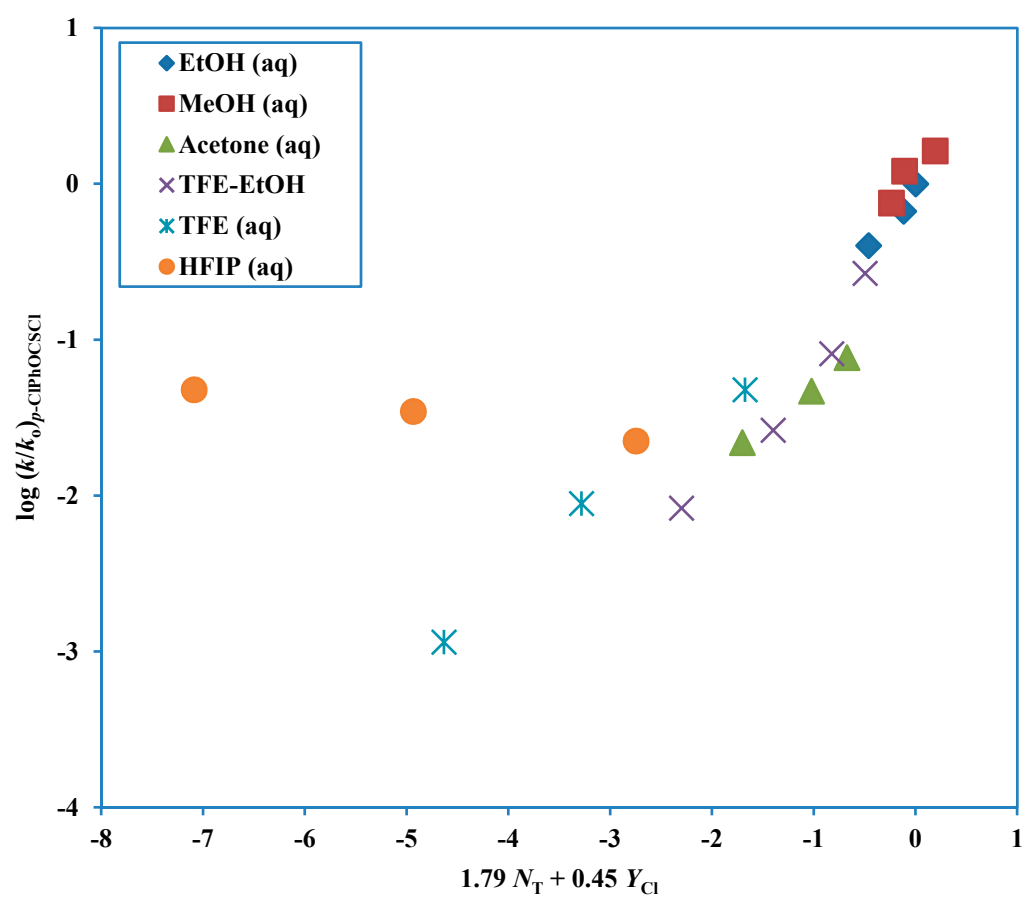

Another way of investigating the change in mechanism is in terms of the $l / m$ ratios listed in Table 3 . It can be seen that, for $p-\mathrm{Me}, p-\mathrm{H}, p-\mathrm{F}$, and $p-\mathrm{Cl}$ substituents, the ratios are fairly constant at 3.54, 3.36, 3.26, and 3.98 for the A-E pathway and at $0.37,0.42,0.60$, and 0.45 for the ionization pathway.

Although there have been several studies of fluoroformate esters [9], no examples of kinetic studies of fluorothioformate esters were found. There is, however, a report of a kinetic study of a fluorothionoformate ester [75]. Phenyl fluorothionoformate was prepared from commercially available chlorothionoformate as described by Bay [78].

The corresponding chlorothioformate reacted in Grunwald-Winstein equation studies (Table 3) by a dominant addition-elimination pathway in solvents of relatively high nucleophilicity and low ionizing power, which converted over to a dominant ionization pathway in aqueous fluoroalcohols. Since the strong carbon-fluorine bond severely limits the operation of an ionization mechanism, as shown by the 
$k_{\mathrm{F}} / k_{\mathrm{Cl}}$ value of $3.3 \times 10^{-8}$ for the hydrolysis in $100 \% \mathrm{H}_{2} \mathrm{O}$ of $p$-dimethylaminobenzoyl halides [32], the ratio is a powerful indicator of the reaction mechanism under the solvolysis conditions $[31,32]$.

For the solvolyses of phenyl fluorothionoformate, the extended Grunwald-Winstein equation gave a linear plot over the full range of solvents with $l$ and $m$ values, consistent with the operation of an addition-elimination mechanism with the addition step rate-determining. The correlation data is presented in Table 3. The $l / m$ ratio of 3.38 is within the range of values previously found for the A-E branch of the correlation analyses of aryl chlorothionoformate solvolyses.

Another tool which can be used to test for mechanism is to do a direct correlation of the $\log \left(k / k_{\mathrm{o}}\right)$ values against the corresponding values for the solvolysis of a substrate with previously assigned mechanism, such in the use of phenyl chloroformate solvolyses as a prototype for a chloroformate solvolyzing by the addition-elimination mechanism. This more direct approach, using similarity models and removing the need to have scales of solvent properties available has been favored and extensively used by Bentley [79]. In comparisons of this type, a good linear correlation will be obtained if the $l / m$ ratios for the two solvolyses are similar. A plot of this type for phenyl fluorothionoformate $\log \left(k / k_{0}\right)$ values against the corresponding values for phenyl chloroformate (Figure 4) is nicely linear, consistent with $l / m$ values of 3.38 (Table 3 ) and 2.96 (Table 2), respectively. The slope, actually at a value of 0.92 can be estimated as the ratio of either the $l$ or the $m$ values to give estimates of 0.80 and 0.70 , respectively.

Figure 4. Plot of $\log \left(k / k_{\mathrm{o}}\right)$ for solvolyses of phenyl fluorothionoformate at $10.0{ }^{\circ} \mathrm{C}$ against $\log \left(k / k_{\mathrm{o}}\right)$ for solvolyses of phenyl chloroformate at $25.0^{\circ} \mathrm{C}$.

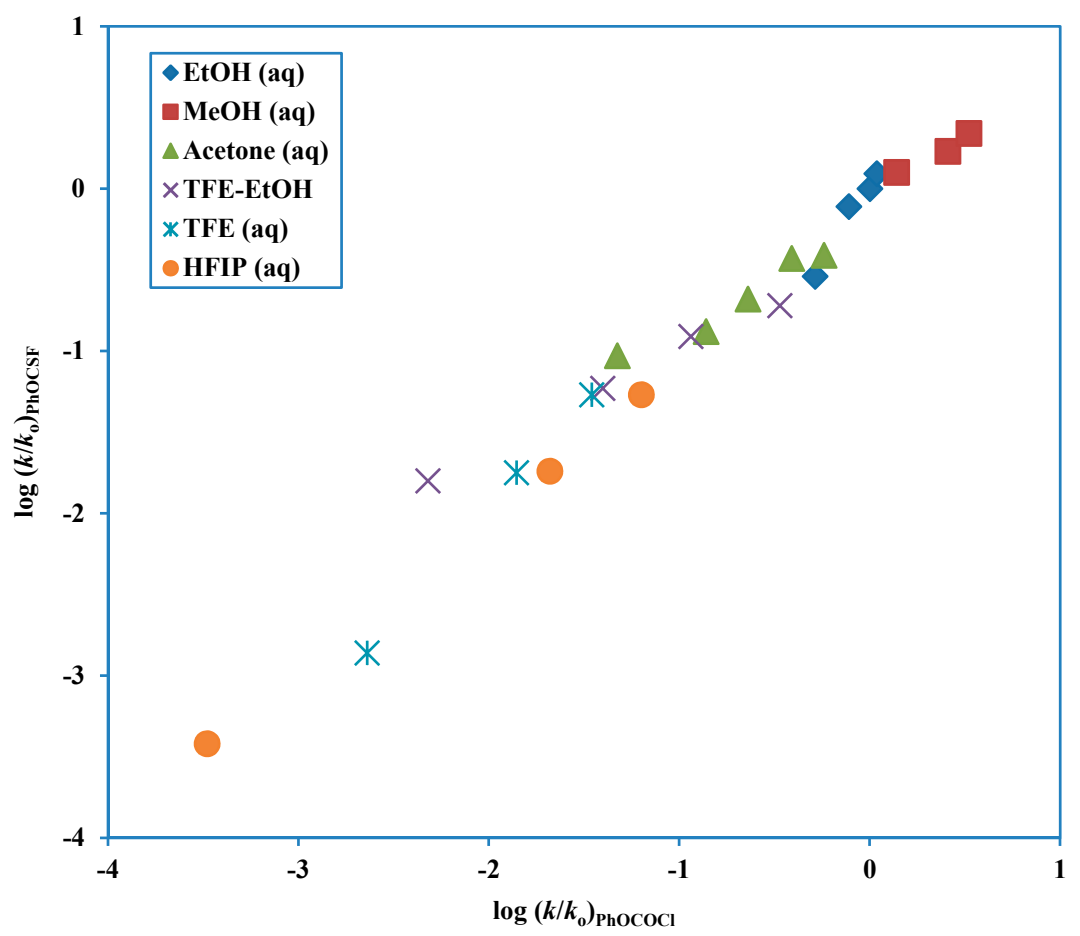

As one predicts from the enormous retardation, on replacing chlorine by fluorine, to be expected for the competing ionization pathway, a single Grunwald-Winstein correlation (for the A-E pathway) can be applied across the full range of the studied solvent compositions. Also, the $k \mathrm{MeOH} / k_{\mathrm{MeOD}}$ value of 
$2.11 \pm 0.02$ is consistent with the A-E pathway. At $25.0{ }^{\circ} \mathrm{C}$, the $k_{\mathrm{F}} / k_{\mathrm{Cl}}$ ratio was 493 in $100 \%$ methanol, 551 in 100\% ethanol, 867 in 80\% ethanol, 64 in 70\% TFE, and 0.21 in 90\% HFIP. The considerably lower ratios in the solvents with high fluoroalcohol content follow from the $k_{\mathrm{Cl}}$ value having a large superimposed component from a dominant ionization pathway.

\section{Chlorodithioformates}

The preparation and synthetic applications of chlorodithioformate esters have been reviewed [80]. They have been used to provide hydrophobic prodrugs by interaction with nucleic acid bases, nucleosides, and nucleotides [81].

McKinnon and Queen [69] found that, relative to the chlorothioformates and chlorothionoformates, the chlorodithioformates were of very low solubility in water and, accordingly, they were studied in $70 \%$ acetone. Temperature variation for the solvolyses of the methyl ester led to an entropy of activation of $-3.7 \mathrm{cal} \cdot \mathrm{mol}^{-1} \cdot \mathrm{K}^{-1}$, consistent with an ionization pathway. An ionization pathway was also indicated by the relative rates for a series of chlorodithioformate esters in $70 \%$ acetone at $4.9{ }^{\circ} \mathrm{C}$ : $\mathrm{C}_{6} \mathrm{H}_{5}$ (1.0); $\mathrm{CH}_{3}$ (5.1); $\mathrm{C}_{2} \mathrm{H}_{5}$ (32); $i-\mathrm{C}_{3} \mathrm{H}_{7}$ (170).

The effect of added salts was instructive [82]. Addition of sodium perchlorate gave modest increases in rate, suggesting a positive salt effect. Addition of sodium chloride led to a reduced rate, indicating common-ion return, which must be from free carbocations. Addition of azide ion led to reduced amounts of acid production and formation of products from azide attack (Scheme 5). In this scheme $[82,83]$ the azide product, which spontaneously cyclizes, is produced directly by a bimolecular pathway and indirectly by capturing the carbocation produced. Added chloride ion can compete for capture of the carbocation by an external return pathway or the carbocation can be captured by water from the solvent to give a half-ester, which loses COS and gives the methanethiol. The kinetics in the presence of a relatively large concentration ( 0.05 to $0.2 \mathrm{~mol} / \mathrm{L})$ of azide ion is first-order in substrate and first-order in azide ion [83] and the solvolysis reaction observed in its absence is almost totally suppressed.

Scheme 5. Reactions pathways in $70 \%$ acetone containing azide ion for reaction of (methylthio)thiocarbonyl chloride (methyl chlorodithioformate).

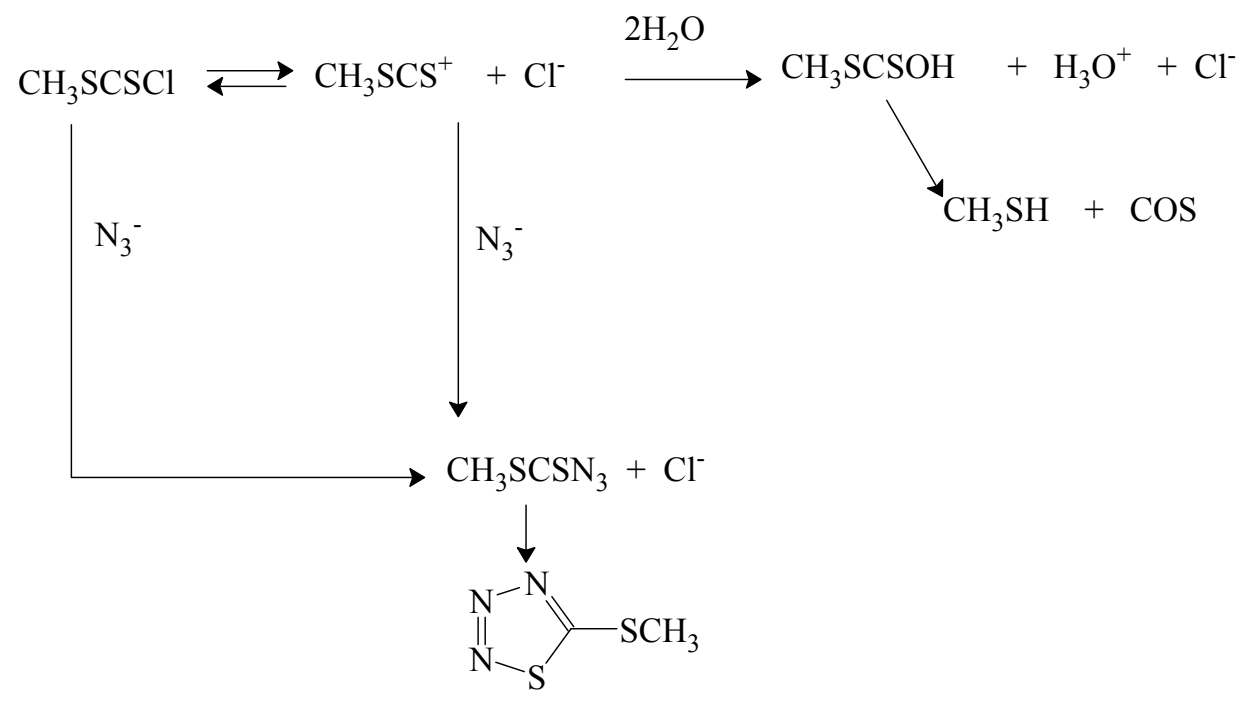


Application of the Grunwald-Winstein equation was initially done with fourteen solvents and a good correlation was obtained, with an $l$ value of $0.55 \pm 0.09$, and an $m$ value of $0.84 \pm 0.08$ $(R=0.967)$, for an $l / m$ ratio of 0.65 [70]. The correlation included runs at $25.0{ }^{\circ} \mathrm{C}$ in aqueous TFE as well as in EtOH-H$-\mathrm{H}_{2} \mathrm{O}, \mathrm{MeOH}-\mathrm{H}_{2} \mathrm{O}$ and acetone-water. Subsequently additional values became available and also a value for methan(ol- $d$ ), allowing a $k \mathrm{MeOH} / k_{\mathrm{MeOD}}$ ratio of 1.49 to be calculated [84], consistent with the earlier proposed ionization pathway.

With a total of 31 solvolyses now available the correlations were considerably improved and, again using the extended Grunwald-Winstein equation, a good correlation (Figure 5) was obtained for all solvents with an $l$ value of $0.69 \pm 0.05, m$ value of $0.95 \pm 0.03, c$ value of $0.18 \pm 0.05, R$-value of 0.987 and $F$-value of 521 [72] (last entry of Table 3). The $l$ and $m$ values are both slightly increased relative to the 14 data point correlation, as is the $l / m$ ratio of 0.72 , which remains, however, in the range consistent with an ionization mechanism.

Figure 5. The plot of $\log \left(k / k_{0}\right)$ for solvolyses of phenyl chlorodithioformate in 31 pure and binary solvents at $25.0{ }^{\circ} \mathrm{C}$ against $\left(0.69 N_{\mathrm{T}}+0.95 Y_{\mathrm{Cl}}\right)$.

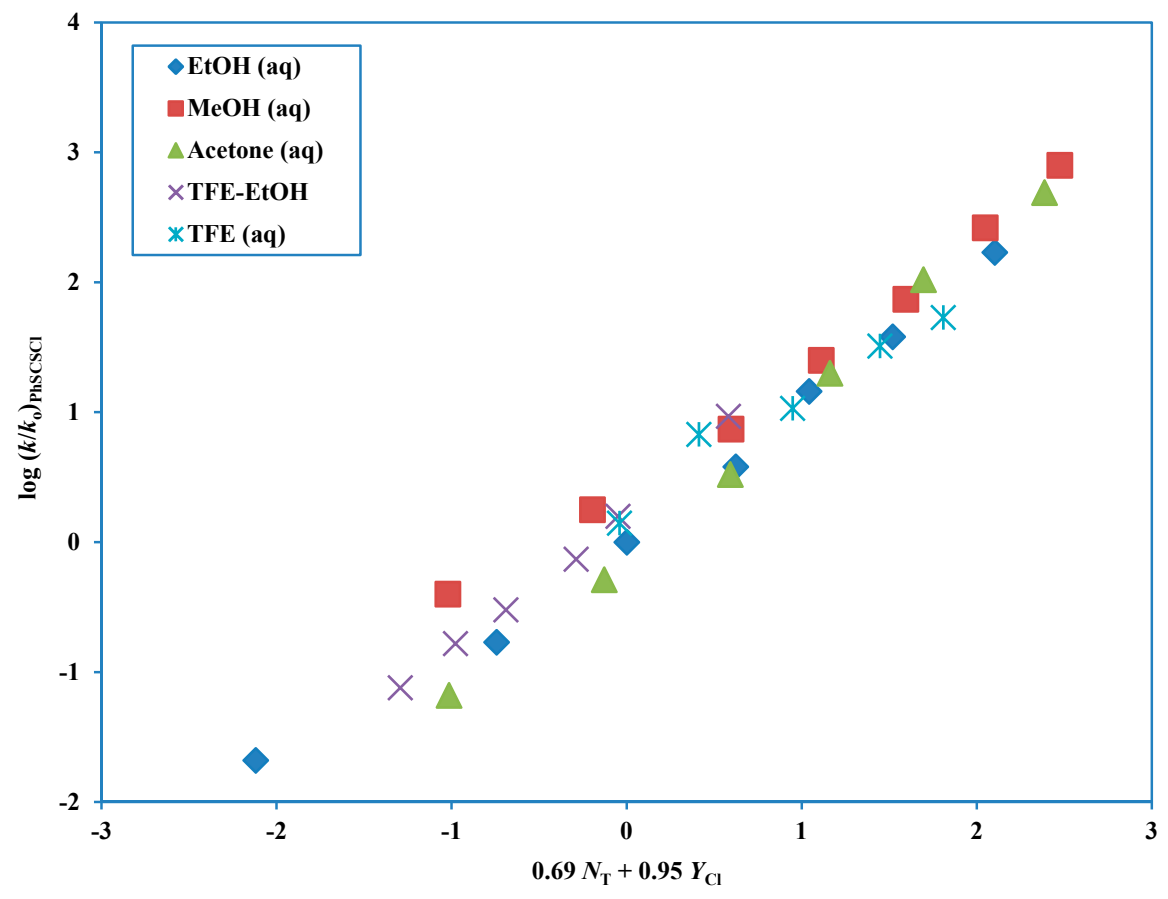

As one would predict, since replacing either oxygen of phenyl chloroformate with sulfur leads to the incursion of an ionization mechanism for solvolyses with fluoroalcohol-rich solvents, replacing both oxygens leads to a further increase in the tendency towards ionization, such that it is now observed over the full range of solvents. Accordingly, while PhOCOCl shows an addition-elimination mechanism over the full range of investigated solvents, $\mathrm{PhSCSCl}$ follows an ionization pathway over the same range of solvents and the intermediate $\mathrm{PhSCOCl}$ and $\mathrm{PhOCSCl}$ both show intermediate sovolysis behavior.

In addition to conclusions drawn from the consideration of the ease of ionization, one should also consider ground-state effects. Indeed, the slow reactions of chloroformates relative to acyl chlorides are largely due to ground-state stabilization, through resonance, in the former [1]. Calculations of this 
stabilization at the HF/6-31G(d) level [79] show a $16 \mathrm{kcal} / \mathrm{mol}$ stabilization for methyl chloroformate relative to methyl chlorothioformate, leading to more energy being needed to break the $\mathrm{C}-\mathrm{Cl}$ bond for a chloroformate, and a faster reaction for the corresponding chlorothioformate in the ionization pathway. The strength of the $\mathrm{C}-\mathrm{Cl}$ bond will be considerably less important when the addition step of an addition-elimination pathway is rate-determining.

\section{Carbamoyl and Thiocarbamoyl Halides}

Although less obviously related to the other substrates of this review, a brief consideration of the RR'NCOCl and RR'NCSCl compounds, in terms of their behavior under solvolytic conditions, can serve as a check on the explanations given for the effects of replacing oxygen by sulfur.

They can be considered as being related to the ROCOCl and $\mathrm{ROCSCl}$ compounds by the replacement of the alkoxy group by an NRR' amino group or in terms of the replacement of the oxygen of the alkoxy group by an NR' group.

It has been postulated that the chlorothioformate has a greater tendency to react by ionization than the chloroformate because, in the incipient acylium ion at the transition state, the sulfur can better carry a positive charge within the resonance hybrid that is being formed (Scheme 6). Bentley [54] has carried out calculations which combine these effects of cation stabilization with the ground-state stabilization effects discussed at the end of the immediately preceding section. In this way he arrived at heterolytic bond dissociation energies for a series of phenyl esters. Values (in $\mathrm{kcal} / \mathrm{mol}$ ) were arrived at of 166.5 for $\mathrm{PhOCOCl}, 153.3$ for $\mathrm{PhSCOCl}, 148.7$ for $\mathrm{PhOCSCl}$, and $143.4 \mathrm{for} \mathrm{PhSCSCl}$. These values are nicely consistent with the observed trends of mechanistic change.

Scheme 6. Resonance-stabilized acylium ion.

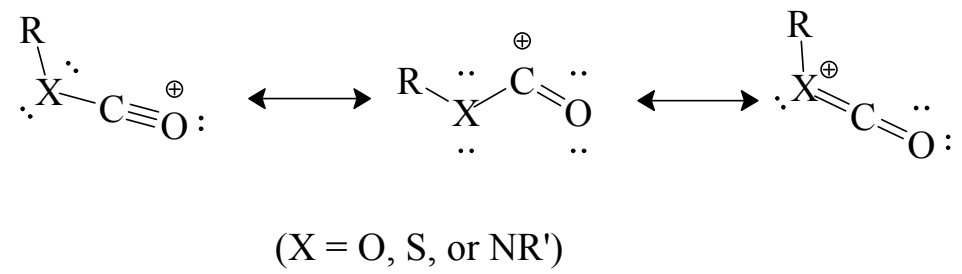

One would expect an even greater tendency towards ionization when a portion of the charge is placed on a nitrogen atom, which is even more capable of carrying a positive charge. It is, indeed, found that an analysis of the solvolyses of $N, N$-dimethylcarbamoyl chloride [85] gives a good linear correlation in an extended Grunwald-Winstein treatment, with an $l$ value of $0.56 \pm 0.05$ and an $m$ value of $0.70 \pm 0.04(R=0.983)$ for an $l / m$ ratio of 0.86 , consistent with an ionization pathway with a relatively large degree of assistance from nucleophilic solvation, or with a loose $\mathrm{S}_{\mathrm{N}} 2$ transition state, with little bond-making and extensive bond-breaking. Similar behavior was also observed for the $N, N$-diphenylcarbamoyl chloride and three $N$-alkyl- $N$-arylcarbamoyl chlorides [72].

A study in terms of the substitution effects in the solvolyses of $N, N$-dialkylcarbamoyl chlorides [86] showed that intensifying the electron release from the alkyl group led to faster reactions and the rates could be correlated using the alkyl group $\sigma^{*}$ values (a scale of the Hammett $\sigma$-value type but devised for this type of situation [87]). The $\varrho^{*}$ values obtained were at values of -4.1 in $50 \%$ aqueous acetone 
and of -3.7 in ethanol, consistent with an appreciable assistance to the solvolysis process from an electron-release by the alkyl groups. A series of corresponding thio-derivatives was studied in $70 \%$ acetone [88]. The sensitivity to changes in $\sigma^{*}$ values was again appreciable, but considerably less than in the earlier study [86]. A value for $Q^{*}$ of -1.73 was observed.

These differences in magnitude are consistent with a reduced demand for electron density from the amino group when the first of the canonical structures in Scheme 6 (with $X=N R^{\prime}$ ) has the oxygen replaced by sulfur which can better carry a positive charge, increasing the contribution of this structure to the overall hybrid. This further increase in stability of the formed carbocation will also reduce the energy content at the transition state and one would expect a faster reaction. This is indeed the case and the ratios of the specific solvolysis rates of $\left(\mathrm{CH}_{3}\right)_{2} \mathrm{NCSCl}$ relative to those for $\left(\mathrm{CH}_{3}\right)_{2} \mathrm{NCOCl}$, at $0.0{ }^{\circ} \mathrm{C}$, of 120 to 344 in ethanol, methanol, and their binary mixtures with water, increasing to $448-1660$ in TFE and mixtures of TFE with $\mathrm{H}_{2} \mathrm{O}$ or ethanol demonstrate large effects. In a Grunwald-Winstein treatment [19] using the two-term version (Equation (2)) both the $l$ and $m$ values are lower for the thiocarbamoyl derivative than for $N, N$-dimethylcarbamoyl chloride, with values of $0.29 \pm 0.03$ for $l$ and $0.55 \pm 0.06$ for $m(R=0.993)$. The $l / m$ ratio of 0.53 is also considerably lower than the value of 0.86 for $\left(\mathrm{CH}_{3}\right)_{2} \mathrm{NCOCl}$. These reduced values are consistent with the above discussed more stable cation in the presence of sulfur, leading to a lower energy barrier and an earlier transition state for the ionization process involved in its production.

\section{Conclusions}

The introduction of sulfur in $\mathrm{ROCOCl}$ substrates introduces a variety of superimposed mechanisms and the ranges of dominance is dependent on the $\mathrm{R}$ group, the presence of one or two sulfurs, and the types of solvent studied (i.e., on the $N_{\mathrm{T}}$ and $Y_{\mathrm{Cl}}$ values). On the other hand, $N, N$-disubstituted carbamoyl and thiocarbamoyl chlorides favor the ionization pathway.

\section{Acknowledgments}

This work was made possible by grants from the State of Delaware (DE), and federal grants from the National Institute of General Medical Sciences-NIGMS (8 P20 GM103446-13) from the National Institutes of Health (DE-INBRE program), and a National Science Foundation (NSF) EPSCoR grant EPS-0814251 (DE-EPSCoR program). The DE-INBRE and DE-EPSCoR grants were obtained through the leadership of the University of Delaware and the authors sincerely appreciate their efforts.

\section{Conflicts of Interest}

The authors declare no conflict of interest.

\section{References}

1. Kevill, D.N. Chloroformate esters and related compounds. In The Chemistry of the Functional Groups: The Chemistry of Acyl Halides; Patai, S., Ed.; Wiley: New York, NY, USA, 1972; pp. 381-453.

2. Carey, F.A. Organic Chemistry, 4th ed.; McGraw Hill: New York, NY, USA, 2000; pp. 1076-1082. 
3. Jones, J. The Chemical Synthesis of Peptides; Oxford University Press: Oxford, UK, 1991.

4. Crich, D., Ed.; Handbook of Reagents for Organic Synthesis: Reagents for Glycoside, Nucleotide, and Peptide Synthesis; Wiley: New York, NY, USA, 2005.

5. Matzner, M.; Kurkjy, R.P.; Cotter, R.J. The Chemistry of Chloroformates. Chem. Rev. 1964, 64, 645-687.

6. Banerjee, S.S.; Aher, N.; Patel, R.; Khandare, J. Poly(ethylene glycol)-prodrug conjugates: Concepts, Design, and Application. J. Drug Deliv. 2012, 2012, 103973:1-103973:17.

7. Bartel, K.; Gossen, A.; Scheffer, A. Hypoiodite Reaction. Decomposition of Oxalic Acid Halfesters. J. Chem. Soc. C 1971, 3766-3769.

8. Hoffmann, H.M.R.; Iranshahi, L. Synthesis and CuCN-Promoted Cyanation of Iodoformic Esters. J. Org. Chem. 1984, 49, 1174-1176.

9. D’Souza, M.J.; Kevill, D.N. Application of the Grunwald-Winstein Equations to Studies of Solvolytic Reactions of Chloroformate and Fluoroformate Esters. Recent Res. Devel. Organic Chem. 2013, 13, $1-38$.

10. Choppin, A.R.; Rodgers, J.W. Preparation of Di-tert-butyl Carbonate and tert-Butyl Chlorocarbonate. J. Am. Chem. Soc. 1948, 70, 2967-2967.

11. Kevill, D.N.; Weitl, F.L. Kinetics and Mechanism of the Decomposition of 1-Adamantyl Chloroformate. J. Am. Chem. Soc. 1968, 90, 6416-6420.

12. Dang, V.A.; Olofson, R.A.; Wolf, P.R.; Piteau, M.D.; Senet, J.-P.G. A Simple Conversion of 1-Chloroethyl Carbonates to Fluoroformates: Value in the Preparation of Tertiary Fluroformates. J. Org. Chem. 1990, 55, 1847-1851.

13. Dang, V.A.; Olofson, R.A. Advantages of Fluoroformates as Carboalkoxylating Reagents for Polar Reactions. J. Org. Chem. 1990, 55, 1851-1854.

14. Bihel, F.; Delaage, M.; Jouve, C.; Kraus, J.-L.; Pourquie, O.; Williamson, T.-L.; Drouot, C. Isocoumarin Derivatives, Particularly 7-Amino-4-chloro-3-(2-methoxyethoxy)isochromen-1-ones Inhibiting Production of Amyloid Peptide, Preparation, Compositions Containing Them, and Uses. WO0248102, 2002.

15. Kevill, D.N.; Kyong, J.B. Multiple Pathways in the Solvolysis of 1-Adamantyl Fluoroformate. J. Org. Chem. 1992, 57, 258-265.

16. Lee, Y.-W.; Seong, M.H.; Kyong, J.B.; Kevill, D.N. Correlation of the Rates of Solvolysis of $t$-Butyl Fluoroformate Using the Extended Grunwald-Winstein Equation. Bull. Korean Chem. Soc. 2010, 31, 3366-3370.

17. Samano, V.; Robins, M.J. Nucleic Acid Related Compounds. 77. 2'3'-Didehydro-2'3'-dideoxy-2'(and 3')-methylnucleosides via [3,3]-Sigmatropic Rearrangements of 2' (and 3')-Methylene-3' (and 2')-O-thiocarbonyl Derivatives and Radical Reduction of a 2-Chloro-3'-methylene Analog. Can. J. Chem. 1993, 71, 186-191.

18. Khazanchi, R.; Yu, P.-L.; Johnson, F. $N^{2} 3$-Etheno-2'-deoxyguanosine [8,9-Dihydro-9-oxo-2'-deo xy-3- $\beta$-D-ribofuranosylimidazo [2,1-b]purine]: A Practical Synthesis and Characterization. J. Org. Chem. 1993, 58, 2552-2556.

19. Kevill, D.N.; Rudolph, T.M.; D’Souza, M.J. Solvolysis of N,N-Dimethylthiocarbamoyl Chloride: Effect of Sulfur for Oxygen Substitution Upon Kinetics and Product Partitioning. J. Phys. Org. Chem. 2000, 13, 192-196. 
20. Grunwald, E.; Winstein, S. The Correlation of Solvolysis Rates. J. Am. Chem. Soc. 1948, 70, 846-854.

21. Winstein, S.; Grunwald, E.; Jones, H.W. The Correlation of Solvolyses Rates and the Classification of Solvolysis Reactions into Mechanistic Categories. J. Am. Chem. Soc. 1951, 73, 2700-2707.

22. Kevill, D.N.; D’Souza, M.J. Sixty Years of the Grunwald-Winstein Equation: Development and Recent Applications. J. Chem. Res. 2008, 61-66, doi:10.3184/030823408X293189.

23. Kevill, D.N.; Anderson, S.W.; Fujimoto, E.K. Nucleophilicity Studies of Reactions in Which The Displaced Group is a Neutral Molecule. In Nucleophilicity; Harris, J.M., McManus, S.P., Eds.; Advances in Chemistry Series, No. 215; American Chemical Society: Washington, DC, USA, 1987; pp. 269-283.

24. Bentley, T.W.; Carter, G.E. The $\mathrm{S}_{\mathrm{N}} 2-\mathrm{S}_{\mathrm{N}} 1$ Spectrum. 4. Mechanism for Solvolyses of tert-Butyl Chloride: A Revised $Y$ Scale of Solvent Ionizing Power Based on Solvolyses of 1-Adamantyl Chloride. J. Am. Chem. Soc. 1982, 104, 5741-5747.

25. Wells, P.R. Linear Free-Energy Relationships; Academic Press: New York, NY, USA, 1968.

26. Schadt, F.L.; Bentley, T.W.; Schleyer, P.v.R. The $\mathrm{S}_{\mathrm{N}} 2-\mathrm{S}_{\mathrm{N}} 1$ spectrum. 2. Quantitative Treatments of Nucleophilic Solvent Assistance. A Scale of Solvent Nucleophilicities. J. Am. Chem. Soc. 1976, 98, 7667-7674.

27. Kevill, D.N.; Anderson, S.W. An Improved Scale of Solvent Nucleophilicity Based on the Solvolysis of the $S$-Methyldibenzothiophenium Ion. J. Org. Chem. 1991, 56, 1845-1850.

28. Kevill, D.N. Development and Uses of Scales of Solvent Nucleophilicity. In Advances in Quantitative Structure-Property Relationships; Charton, M., Ed.; JAI Press: Greenwich, CT, USA, 1996; Volume 1, pp. 81-115.

29. Bentley, T.W.; Llewellyn, G. Yx Scales of Solvent Ionizing Power. Prog. Phys. Org. Chem. 1990, 17, 121-158.

30. Hoffmann, H.M.R. Ratio of $k_{\mathrm{OTs}} / k_{\mathrm{Br}}$ and the Separation of Charges in Transition States of Solvolytic Displacements. J. Chem. Soc. 1965, 6762-6769.

31. Swain, C.G.; Scott, C.B. Rates of Solvolysis of Some Alkyl Fluorides and Chlorides. J. Am. Chem. Soc. 1953, 75, 246-248.

32. Song, B.D.; Jencks, W.P. Mechanism of Solvolysis of Substituted Benzoyl Halides. J. Am. Chem. Soc. 1989, 111, 8470-8479.

33. Kevill, D.N.; D’Souza, M.J. Correlation of the Rates of Solvolysis of Benzoyl Fluoride. J. Org. Chem. 2004, 69, 7044-7050.

34. Ingold, C.K. Structure and Mechanism in Organic Chemistry, 2nd ed.; Cornell University Press: Ithaca, NY, USA, 1969; pp. 471-473.

35. Queen A. Kinetics of the Hydrolysis of Acyl Chlorides in Pure Water. Can. J. Chem. 1967, 45, 1619-1629.

36. Bentley, T.W.; Llewellyn, G.; McAlister, J.A. SN2 Mechanism for Alcoholysis, Aminolysis, and Hydrolysis of Acetyl Chloride. J. Org. Chem. 1996, 61, 7927-7932.

37. Kevill, D.N.; Foss, F.D. Acylation Mechanisms in Aprotic Solvents. I. Methanolysis of p-Nitrobenzoyl Chloride in Acetonitrile. J. Am. Chem. Soc. 1969, 91, 5054-5059. 
38. Castro, E.A. Kinetics and Mechanisms of Reactions of Thiol, Thiono and Dithio Analogues of Carboxylic Esters with Nucleophiles. An Update. J. Sulfur Chem. 2007, 28, 401-429.

39. Potts, K.T.; Sapino, C. Thiocarbonyl Halides; In The Chemistry of the Functional Groups: The Chemistry of Acyl Halides; Patai, S., Ed.; Wiley: New York, NY, USA, 1972; pp. 356-358.

40. Queen, A.; Nour, T.A.; Paddon-Row, M.N.; Preston, K. Kinetics of the Hydrolysis of Thiochloroformate Esters in Pure Water. Can. J. Chem. 1970, 48, 522-527.

41. Queen, A.; Nour, T.A.; Bock, E. Electric Moments, Sulfur Bonding, and Confirmations of Substituted Thiochloroformate Esters in Benzene Solution. Can. J. Chem. 1969, 47, 343-348.

42. Kevill, D.N.; D'Souza, M.J. Correlation of the Rates of Solvolysis of Phenyl Chloroformate. J. Chem. Soc. Perkin Trans. 2, 1997, 1721-1724, doi:10.1039/A701140G.

43. Kevill, D.N.; Bond, M.W.; D’Souza, M.J. Dual Pathways in the Solvolyses of Phenyl Chlorothioformate. J. Org. Chem. 1997, 62, 7869-7871.

44. D’Souza, M.J.; Hailey, S.M.; Kevill, D.N. Use of Empirical Correlations to Determine Solvent Effects in the Solvolysis of S-Methyl Chlorothioformate. Int. J. Mol. Sci. 2010, 11, 2253-2266.

45. Kevill, D.N.; D'Souza, M.J. Concerning the Two Reaction Channels for the Solvolyses of Ethyl Chloroformate and Ethyl Chlorothioformate. J. Org. Chem. 1998, 63, 2120-2124.

46. D’Souza, M.J.; McAneny, M.J.; Kevill, D.N.; Kyong, J.B.; Choi, S.H. Kinetic Evaluation of the Solvolysis of Isobutyl Chloro- and Chlorothioformate Esters. Beilstein J. Org. Chem. 2011, 7, 543-552.

47. D’Souza, M.J.; Mahon, B.P.; Kevill, D.N. Analysis of the Nucleophilic Solvation Effects in Isopropyl Chlorothioformate Solvolysis. Int. J. Mol. Sci. 2010, 11, 2597-2611.

48. Kyong, J.B.; Lee, Y.; D’Souza, M.J.; Mahon, B.P.; Kevill, D.N. Correlation of the Rates of Solvolysis of tert-Butyl Chlorothioformate and Observations Concerning Reaction Mechanism. Eur. J. Chem. 2012, 3, 267-272.

49. Kevill, D.N.; Kim, J.C.; Kyong, J.B. Correlation of the Rates of Solvolysis of Methyl Chloroformate with Solvent Properties. J. Chem. Res. Synop. 1999, 150-151, doi:10.1039/A701140G.

50. Kyong, J.B.; Kim, Y.G.; Kim, D.K.; Kevill, D.N. Dual Pathways in the Solvolyses of Isopropyl Chloroformate. Bull. Korean Chem. Soc. 2000, 21, 662-664.

51. D’Souza, M.J.; Reed, D.N.; Erdman, K.J.; Kyong, J.B.; Kevill, D.N. Grunwald-Winstein Analysis-Isopropyl Chloroformate Solvolysis Revisited. Int. J. Mol. Sci. 2009, 10, 862-879.

52. Jencks, W.P. How Does a Reaction Change Its Mechanism? Chem. Soc. Rev. 1981, 10, 345-375.

53. Olah, G.A.; Schilling, P.; Bollinger, J.M.; Nishimura, J. Stable Carbocations. CLXIII. Complexing, Ionization, and Fragmentative Alkylcarbenium Ion Formation from Alkyl Haloformates, Thiohaloformates, and Halosulfites with Antimony Pentafluoride. J. Am. Chem. Soc. 1974, 96, 2221-2228.

54. Bentley, T.W. Structural Effects on the Solvolytic Reactivity of Carboxylic and Sulfonic Acid Chlorides. Comparisons with Gas-Phase Data for Cation Formation. J. Org. Chem. 2008, 73, 6251-6257.

55. D’Souza, M.J.; Sandosky, B.; Fernandez-Bueno, G.A.; McAneny, M.J.; Kevill, D.N. LFER Studies Evaluating Solvent Effects on an $\alpha$-Chloro-and two $\beta, \beta, \beta$-Trichloro-Ethyl Chloroformate Esters. Can. Chem. Trans. 2014, 2, 160-174. 
56. Koh, H.J.; Kang, S.J.; Kevill, D.N. Kinetic Studies of the Solvolyses of 2,2,2-Trich loro-1,1-Dimethylethyl Chloroformate. Bull. Korean Chem. Soc. 2010, 31, 835-839.

57. Kyong, J.B.; Won, H.; Kevill, D.N. Application of the Extended Grunwald-Winstein Equation to Solvolyses of $n$-Propyl Chloroformate. Int. J. Mol. Sci. 2005, 6, 87-96.

58. Lim, G.T.; Lee, Y.H.; Ryu, Z.H. Further Kinetic Studies of Solvolytic Reactions of Isobutyl Chloroformate in Solvents of High Ionizing Power under Conductometric Conditions. Bull. Korean Chem. Soc. 2013, 34, 615-621.

59. Bentley, T.W.; Jones, R.O. New Rate-Product Correlations for General-Base Catalyzed Reactions in Alcohol-Water Mixtures. J. Chem. Soc. Perkin Trans. 2 1992, 743-744, doi:10.1039/P29920000743.

60. Rahmathalluah, S.M.; Hall, J.E.; Bender, B.C.; McCurdy, D.R.; Tidwell, R.R.; Boykin, D.W. Prodrugs for Amidines: Synthesis and Anti-Pneumocytis carinii Activity of Carbamates of 2,5-bis(4-amidinophenyl)furan. J. Med. Chem. 1999, 42, 3994-4000.

61. Bose, D.S.; Goud, P.R. Aryl Chlorothionoformates: A New Versatile Reagent for the Preparation of Nitriles and Isonitriles Under Mild Conditions. Tetrahedron Lett. 1999, 40, 747-748.

62. Millan, D.S.; Prager, R.H. The Dealkylation of Tertiary Aliphatic Amines with Phenyl Chlorothionoformate. Tetrahedron Lett. 1998, 39, 4387-4390.

63. Millan, D.S.; Prager, R.H. Phenyl Chloro(thionoformate): A New Dealkylating Agent of Tertiary Amines. Aust. J. Chem. 1999, 52, 841-850.

64. Castro, E.A.; Cubillos, M.; Santos, J.G. Kinetics and Mechanism of the Aminolysis of Phenyl and 2-Nitrophenyl Chlorothionoformates. J. Org. Chem. 1997, 62, 4394-4397.

65. Castro, E.A. Kinetics and Mechanisms of Reactions of Thiol, Thiono, and Dithio Analogues of Carboxylic Esters with Nucleophiles. Chem. Rev. 1999, 99, 3505-3524.

66. Castro, E.A.; Cubillos, M.; Santos, J.G. Kinetics and Mechanisms of the Pyridinolysis of Phenyl and 4-Nitrophenyl Chlorothionoformates. Formation and Hydrolysis of 1-(Aryloxythiocarbonyl)pyridinium Cations. J. Org. Chem. 2004, 69, 4802-4807.

67. Oh, H.K.; Ha, J.S.; Sung, D.D.; Lee, I. Aminolysis of Aryl Chlorothionoformates with Anilines in Acetonitrile: Effects of Amine Nature and Solvent on the Mechanism. J. Org. Chem. 2004, 69, 8219-8223.

68. Castro, E.A.; Aliaga, M.; Campodonico, P.R.; Leis, J.R.; Garcia-Rio, L.; Santos, J.G. Reactions of Aryl Chlorothionoformates with Quinuclidines. A Kinetic Study. J. Phys. Org. Chem. 2007, 21, $102-107$.

69. McKinnon, D.M.; Queen, A. Kinetics and Mechanism for the Hydrolysis of Chlorothionoformate and Chlorodithioformate Esters in Water and Aqueous Acetone. Can. J. Chem. 1972, 50, 1401-1406.

70. Kevill, D.N.; D'Souza, M.J. Correlation of the Rates of Solvolysis of Phenyl Chlorothionoformate and Phenyl Chlorodithioformate. Can. J. Chem. 1999, 77, 1118-1122.

71. Koo, I.S.; Yang, K.; Kang, D.H.; Park, H.J.; Kang, K.; Lee, I. Transition-State Variation in the Solvolyses of Phenyl Chlorothionoformate in Alcohol-Water Mixtures. Bull. Korean Chem. Soc. 1999, 20, 577-580.

72. Kevill, D.N.; Koyoshi, F.; D’Souza, M.J. Correlation of the Specific Rates of Solvolysis of Aromatic Carbamoyl Chlorides, Chloroformates, Chlorothionoformates, and Chlorodithioformates Revisited. Int. J. Mol. Sci. 2007, 8, 346-352. 
73. D’Souza, M.J.; Hampton, O.N.; Sansbury, B.M.; Kevill, D.N. Evaluation of Electronic Effects in the Solvolyses of $p$-Methylphenyl and $p$-Chlorophenyl Chlorothionoformate Esters. J. Chem. 2013, 2013, 248534:1-248534:9.

74. D’Souza, M.J.; Hailey, S.M.; Mahon, B.P.; Kevill, D.N. Understanding Solvent Effects in the Solvolyses of 4-Fluorophenyl Chlorothionoformate. Chem. Sci. J. 2011, 2011, 1-9.

75. Choi, S.H.; Seong, M.H.; Lee, Y.-W.; Kyong, J.B.; Kevill, D.N. Correlation of the Rates of Solvolysis of Phenyl Fluorothionoformate. Bull. Korean Chem. Soc. 2011, 32, 1268-1272.

76. Csunderlik, C.; Bacaloglu, R.; Ostrogovich, G. Nucleophilic Substitution in Carbonic Acid Derivatives. IV. Kinetics and Mechanism of Hydrolysis of $O$-Aryl Chlorothiocarbonates. J. Prakt. Chem. 1975, 317, 73-80.

77. Ostrogovich, G.; Csunderlik, C.; Bacaloglu, R. Nucleophilic Substitutions to Carbonyl Derivatives. III. Kinetics and Mechanism of Carbonyl Arylester Chloride Hydrolysis. J. Prakt. Chem. 1975, 317, 62-72.

78. Bay, E. Preparation of Thiophenols from Phenols. U.S. Patent US4754072, 1988.

79. Bentley, T.W.; Harris, H.C.; Ryu, Z.H.; Lim, G.T.; Sung, D.D.; Szajda, S.R. Mechanisms of Solvolyses of Acid Chlorides and Chloroformates. Chloroacetyl and Phenylacetyl Chloride as Similarity Models. J. Org. Chem. 2005, 70, 8963-8970.

80. El-Sayed, I.; Abdel-Megeed, M.F.; Yassin, S.M.; Senning, A. The Chemistry of Chlorodithioformates. Sulfur Rep. 1995, 16, 235-297.

81. Fromhold, M.; Partridge, J. N-4 Derivatives of Deoxycytidine Prodrugs as Anti-HIV and Antitumor Agents. PCT Int. Appl. WO2013036846 (A2), 2013.

82. Queen, A.; Matts, T.C. Mechanisms of Nucleophilic Substitution Reactions. The Reaction of Methyl Chlorodithioformate with Azide Ions in 70\% Aqueous Acetone. Tetrahedron Lett. 1975, 1503-1506, doi:10.1016/S0040-4039(00)72180-0.

83. Queen, A.; McKinnon, D.M.; Bell, A.W. The Kinetics of the Reactions of Chlorodithioformate Esters with Azide Ions in 70\% Aqueous Acetone. Can. J. Chem. 1976, 54, 1906-1909.

84. An, S.K.; Yang, J.S.; Cho, J.M; Yang, K.; Lee, J.P.; Bentley, T.W.; Lee, I.; Koo, I.S. Correlation of the Rates of Solvolysis of Phenyl Chlorodithioformate. Bull. Korean Chem. Soc. 2002, 23, 1445-1450.

85. Kevill, D.N.; Oldfield, A.J.; D'Souza, M.J. Correlation of the Rates of Solvolysis of N,N-Dimethylcarbamoyl Chloride. J. Chem. Res. Synop. 1996, 122-123.

86. Bacaloglu, R.; Dăescu, C.; Ostrogovich, G. Nucleophilic Substitution in Carbonic Acid Derivatives. II. Kinetics and Mechanism of the Solvolyses of $N, N$-Dialkylcarbamoyl Chlorides. J. Chem. Soc., Perkin Trans. 2 1972, 1011-1015, doi:10.1039/P29720001011.

87. Leffler, J.E.; Grunwald, E. Rates and Equilibria of Organic Reactions; Wiley: New York, NY, USA, 1963; pp. 219-227.

88. Bacaloglu, R.; Dăescu, C. Nucleophilic Substitution on Carboxylic Acid Derivatives. X. Kinetics and Mechanism of the Hydrolysis of N,N-Disubstituted Thiocarbamic Acid Chlorides. Rev. Roum. Chim. 1977, 22, 977-985.

(C) 2014 by the authors; licensee MDPI, Basel, Switzerland. This article is an open access article distributed under the terms and conditions of the Creative Commons Attribution license (http://creativecommons.org/licenses/by/4.0/). 